\title{
Replication of newly proposed TNM staging system for medullary thyroid carcinoma: a nationwide study
} \author{
Ulla Feldt-Rasmussen ${ }^{6}$, Sten Schytte ${ }^{7}$, Stefano Christian Londero ${ }^{7}$, Henrik Baymler Pedersen ${ }^{8}$, \\ Kim Brixen ${ }^{2}$ and Christian Godballe ${ }^{1}$ on behalf of Danish Thyroid Cancer Group (DATHYRCA)

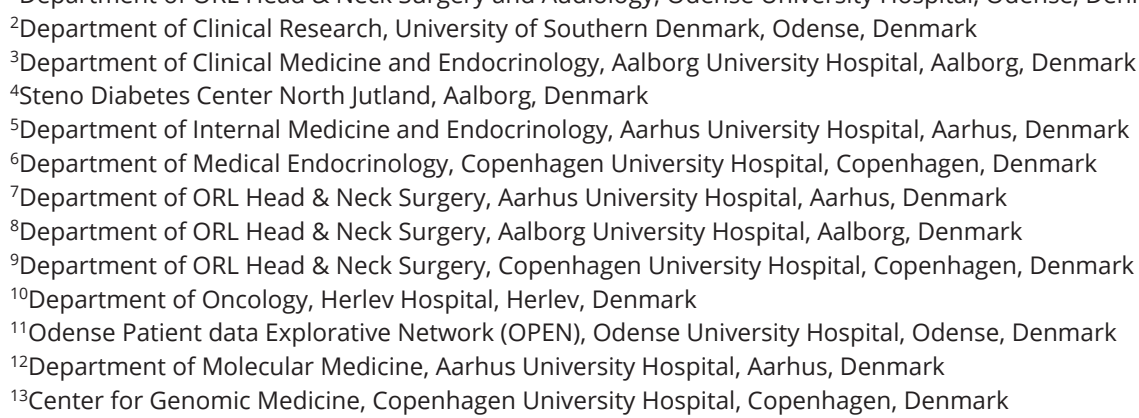

Jes Sloth Mathiesen ${ }^{1,2}$, Jens Peter Kroustrup ${ }^{3}$, Peter Vestergaard ${ }^{3,4}$, Per Løgstrup Poulsen ${ }^{5}$, Åse Krogh Rasmussen ${ }^{6}$, Christoffer Holst Hahn ${ }^{9}$, Jens Bentzen ${ }^{10}$, Sören Möller ${ }^{2,11}$, Mette Gaustadnes ${ }^{12}$, Maria Rossing ${ }^{13}$, Finn Cilius Nielsen ${ }^{13}$,

Correspondence should be addressed to J S Mathiesen: jes_mathiesen@yahoo.dk

\begin{abstract}
A recent study proposed new TNM groupings for better survival discrimination among stage groups for medullary thyroid carcinoma (MTC) and validated these groupings in a population-based cohort in the United States. However, it is unknown how well the groupings perform in populations outside the United States. Consequently, we conducted the first population-based study aiming to evaluate if the recently proposed TNM groupings provide better survival discrimination than the current American Joint Committee on Cancer (AJCC) TNM staging system (seventh and eighth edition) in a nationwide MTC cohort outside the United States. This retrospective cohort study included 191 patients identified from the nationwide Danish MTC cohort between 1997 and 2014. In multivariate analysis, hazard ratios for overall survival under the current AJCC TNM staging system vs the proposed TNM groupings with stage I as reference were 1.32 ( $95 \%$ Cl: $0.38-4.57$ ) vs 3.04 (95\% Cl: 1.38-6.67) for stage II, 2.06 (95\% Cl: $0.45-9.39)$ vs 3.59 (95\% Cl: 1.61-8.03) for stage III and 5.87 (95\% Cl: 2.02-17.01) vs 59.26 (20.53-171.02) for stage IV. The newly proposed TNM groupings appear to provide better survival discrimination in the nationwide Danish MTC cohort than the current AJCC TNM staging. Adaption of the proposed TNM groupings by the current AJCC TNM staging system may potentially improve accurateness in survival discrimination. However, before such an adaption further population-based studies securing external validity are needed.
\end{abstract}

Key Words

thyroid

- endocrine cancers

- rare diseases/syndromes https://ec.bioscientifica.com https://doi.org/10.1530/EC-18-0494 (c) 2019 The authors Published by Bioscientifica Ltd

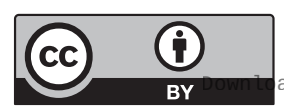

This work is licensed under a Creative Commons Attribution 4.0 International License. ded from Bioscientifica.com at 04/26/2023 12:40:18PM
Endocrine Connections (2019) 8, 1-7 


\section{Introduction}

Medullary thyroid carcinoma (MTC) is a rare neuroendocrine tumor with an incidence of 0.19 per 100,000 per year and a prevalence of 3.8 per 100,000 inhabitants. MTC is divided into a sporadic and hereditary type accounting for approximately 75 and $25 \%$, respectively (1).

MTC can display a highly variable biological behavior, ranging from indolent to very aggressive $(2,3,4)$. This necessitates strong outcome predictors, for example, the American Joint Committee on Cancer (AJCC) TNM staging system $(5,6,7)$. The current AJCC TNM version (seventh and eighth edition) by large mirrors that for papillary and follicular thyroid carcinoma in spite of the fact that MTC differs considerably from the other histological subtypes (2). For this and other reasons several studies have questioned the accuracy of the AJCC TNM staging system for MTC and thus proposed different modifications $(3,8,9,10)$.

Based on data from the US National Cancer Database (11), a large population-based study recently proposed new TNM groupings for better discrimination of mortality risk among the stage groups (2). Application of the proposed TNM groupings to a data set from the Surveillance, Epidemiology, and End Results Program (12) demonstrated a better stage separation compared to that of the current AJCC TNM staging system (2). In brief, overall differences between the current AJCC TNM staging system and the newly proposed groupings include categorization of patients with small tumors and local metastases in stages I-II and inclusion of only patients with distant metastases in stage IV in the proposed TNM groupings. It is however unknown how well these groupings perform in populations outside the United States.

Consequently, we conducted the first populationbased study aiming to evaluate if the recently proposed TNM groupings provide better survival discrimination than the current AJCC TNM staging system in a nationwide MTC cohort outside the United States.

\section{Patients and methods}

\section{Patients}

This retrospective cohort study included 191 unique patients diagnosed with MTC in Denmark between January 1, 1997, and December 31, 2014.

An MTC cohort, initially comprising 476 patients diagnosed with MTC in Denmark between January 1960 and December 2014, was constructed through three nationwide registries: the Danish Thyroid Cancer Database, the Danish Cancer Registry and the Danish Pathology Register $(13,14,15)$. This has been described in detail previously $(1,16)$. The Danish MTC cohort is subdivided by year of diagnosis into an uncertain period (1960-1996) where complete coverage could not be guaranteed and into a nationwide period (1997-2014) where coverage of the entire country was considered complete. For the purpose of this study, we extracted the 224 patients diagnosed in the nationwide period. Of the 224 patients, four were excluded as they were diagnosed by autopsy. Furthermore, for the best possible replication, our cohort was trimmed according to the cohort from the study proposing new TNM groupings (2). We therefore additionally excluded 29 patients: those $<18$ years at diagnosis $(n=10)(16,17,18,19$, $20)$, those with insufficient TNM data $(n=2)$ and those who underwent less surgery than hemithyroidectomy $(n=17)$. This resulted in 191 patients with histologically verified MTC.

The investigation was approved by the Danish Health Authority (3-3013-395/3) and the Danish Data Protection Agency (18/17801). Once approved by the former, patient consent is not necessary according to the Danish legislation.

\section{Methods}

Data were provided by the Danish Thyroid Cancer Database (13). Where this was insufficient, data were drawn from the Danish Cancer Registry (14), the Danish Pathology Register (15) or medical records.

Covariates were age, sex, year of diagnosis and TNM stage. Also patients were classified according to MTC type as sporadic or hereditary. This was primarily based on the absence or presence of rearranged during transfection (RET) germline mutations. RET testing and MTC classification has been described elsewhere $(1,21)$. Staging was performed according to the current AJCC TNM staging system (seventh and eighth edition) $(22,23)$ and according to the newly proposed TNM groupings (2) (Table 1). Staging was based on clinical and pathological assessment. If there was a discrepancy, pathological staging overruled clinical.

\section{Survival}

Outcomes were overall and disease-specific survival. Survival time was calculated as the time from MTC

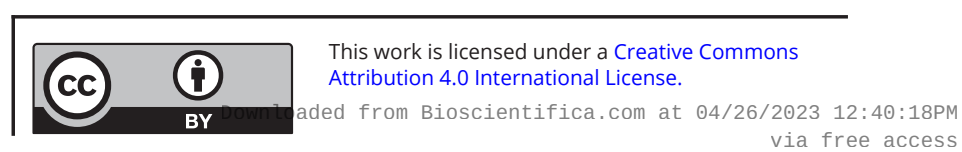


Table 1 Distribution of 191 patients with medullary thyroid carcinoma in Denmark 1997-2014 according to the current ${ }^{\mathrm{a}}$ and proposed TNM staging system ${ }^{b}$.

\begin{tabular}{|c|c|c|c|c|}
\hline Stage & Current & $\boldsymbol{n}(\%)$ & Proposed & $\boldsymbol{n}(\%)$ \\
\hline I & T1N0M0 & $51(27)$ & $\begin{array}{l}\text { T1N0-1aM0 } \\
\text { T2N0M0 }\end{array}$ & $88(46)$ \\
\hline II & T2-3NOMO & $38(20)$ & $\begin{array}{l}\text { T1N1bM0 } \\
\text { T2N1a-1bM0 } \\
\text { T3N0M0 }\end{array}$ & $54(28)$ \\
\hline III & T1-3N1aM0 & $16(8)$ & $\begin{array}{l}\text { T3N1a-1bM0 } \\
\text { T4N0-1bM0 }\end{array}$ & $40(21)$ \\
\hline IV & $\begin{array}{l}\text { T1-3N1bM0 } \\
\text { T4N0-1bM0 } \\
\text { T1-4N0-1bM1 }\end{array}$ & $86(45)$ & T1-4N0-1bM1 & $9(5)$ \\
\hline
\end{tabular}

aStaging was based on the American Joint Committee on Cancer 7th and 8th edition (22, 23); ' bstaging was based on newly proposed groupings (2). $\mathrm{M}$, metastasis; $\mathrm{N}$, node; $\mathrm{T}$, tumor

diagnosis until death, emigration or last follow-up (January 1, 2018), whichever came first. For calculation of overall and disease-specific survival, all deaths and deaths due to MTC were considered as an event, respectively.

\section{Statistical analysis}

Continuous variables are reported as median with interquartile range or mean with standard deviation depending on distribution. Survival data were analyzed by the Kaplan-Meier method. Cox proportional hazards regression model was employed for multivariate analyses. The Akaike criterion was used to estimate the relative quality of statistical models. $P$ values below 0.05 were considered significant. Multiple testing was adjusted by the Bonferroni method (24). All analyses were done using Stata 15.1 (StataCorp).

\section{Results}

A total of 191 patients were included in the study. Patient characteristics are shown in Table 2 . The overall femalemale ratio was 1.51 (95 CI: $1.10-1.95)$. In the 42 patients with hereditary MTC, the following RET mutations were detected: C611W $(n=3), \mathrm{C} 611 \mathrm{Y}(n=29), \mathrm{C} 618 \mathrm{~F}(n=1)$, C618Y ( $n=3)$, C620R $(n=2)$, C634R $(n=1), \mathrm{C} 634 \mathrm{Y}+\mathrm{Y} 791 \mathrm{~F}$ $(n=1)$, V804M $(n=1)$ and M918T $(n=1)$. Several of these families have been reported earlier $(19,25,26,27,28,29)$.

Under the current AJCC TNM staging system 51 (27\%), 38 (20\%), 16 (8\%) and 86 (45\%) were classified in stages I, II, III and IV, respectively. Among the patients in stages I, II, III and IV, 51 (100\%), 9 (24\%), 2 (13\%) and $9(10 \%)$ remained in the same group under the proposed
TNM groupings. The remaining patients were reclassified to lower stage groups. Thus, the distribution of patients under the proposed TNM groupings was 88 (46\%) in stage I, 54 (28\%) in stage II, 40 (21\%) in stage III and 9 (5\%) in stage IV (Table 1$)$.

\section{Survival}

Median follow-up time was 7.15 years (interquartile range, 0.52-20.59). At last follow-up, 59 patients had died. Of these, 37 had died from MTC, while 22 died from other causes.

Overall and disease-specific survival according to the current AJCC TNM staging and the proposed TNM groupings are depicted in Fig. 1 and Table 3. Hazard ratios for adjusted overall survival based on the current AJCC TNM staging and the proposed TNM groupings are presented in Table 4.

Table 2 Characteristics of 191 patients with medullary thyroid carcinoma in Denmark 1997-2014.

\begin{tabular}{|c|c|}
\hline Characteristics & $n(\%)$ \\
\hline \multicolumn{2}{|l|}{ At diagnosis } \\
\hline Age, mean (s.D.) (years) & $53(16)^{a}$ \\
\hline \multicolumn{2}{|l|}{ Sex } \\
\hline Female & $115(60)$ \\
\hline Male & $76(40)$ \\
\hline \multicolumn{2}{|l|}{ MTC type } \\
\hline Sporadic & $149(78)$ \\
\hline Hereditary & $42(22)$ \\
\hline \multicolumn{2}{|l|}{ T category } \\
\hline $\mathrm{T} 1$ & $81(42)$ \\
\hline $\mathrm{T} 2$ & $52(27)$ \\
\hline T3 & $24(13)$ \\
\hline $\mathrm{T} 4$ & $34(18)$ \\
\hline \multicolumn{2}{|l|}{$\mathrm{N}$ category } \\
\hline NO & $91(48)$ \\
\hline $\mathrm{N} 1 \mathrm{a}$ & $20(10)$ \\
\hline $\mathrm{N} 1 \mathrm{~b}$ & $80(42)$ \\
\hline \multicolumn{2}{|l|}{ M category } \\
\hline MO & $182(95)$ \\
\hline M1 & $9(5)$ \\
\hline \multicolumn{2}{|l|}{ Current TNM staging ${ }^{\mathrm{b}}$} \\
\hline I & $51(27)$ \\
\hline II & $38(20)$ \\
\hline III & $16(8)$ \\
\hline IV & $86(45)$ \\
\hline \multicolumn{2}{|l|}{ Thyroid surgery } \\
\hline Total thyroidectomy & $188(98)$ \\
\hline Hemithyroidectomy & $3(2)$ \\
\hline
\end{tabular}

aStandard deviation; ${ }^{b}$ staging was based on the American Joint Committee on Cancer 7th and 8th edition $(22,23)$.

M, metastasis; MTC, medullary thyroid carcinoma; N, node; s.D., standard deviation; $\mathrm{T}$, tumor.

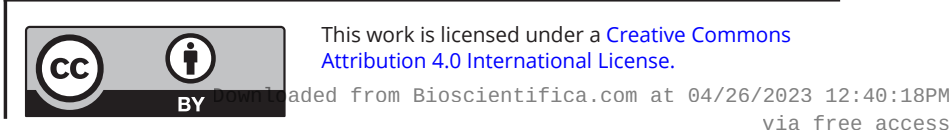



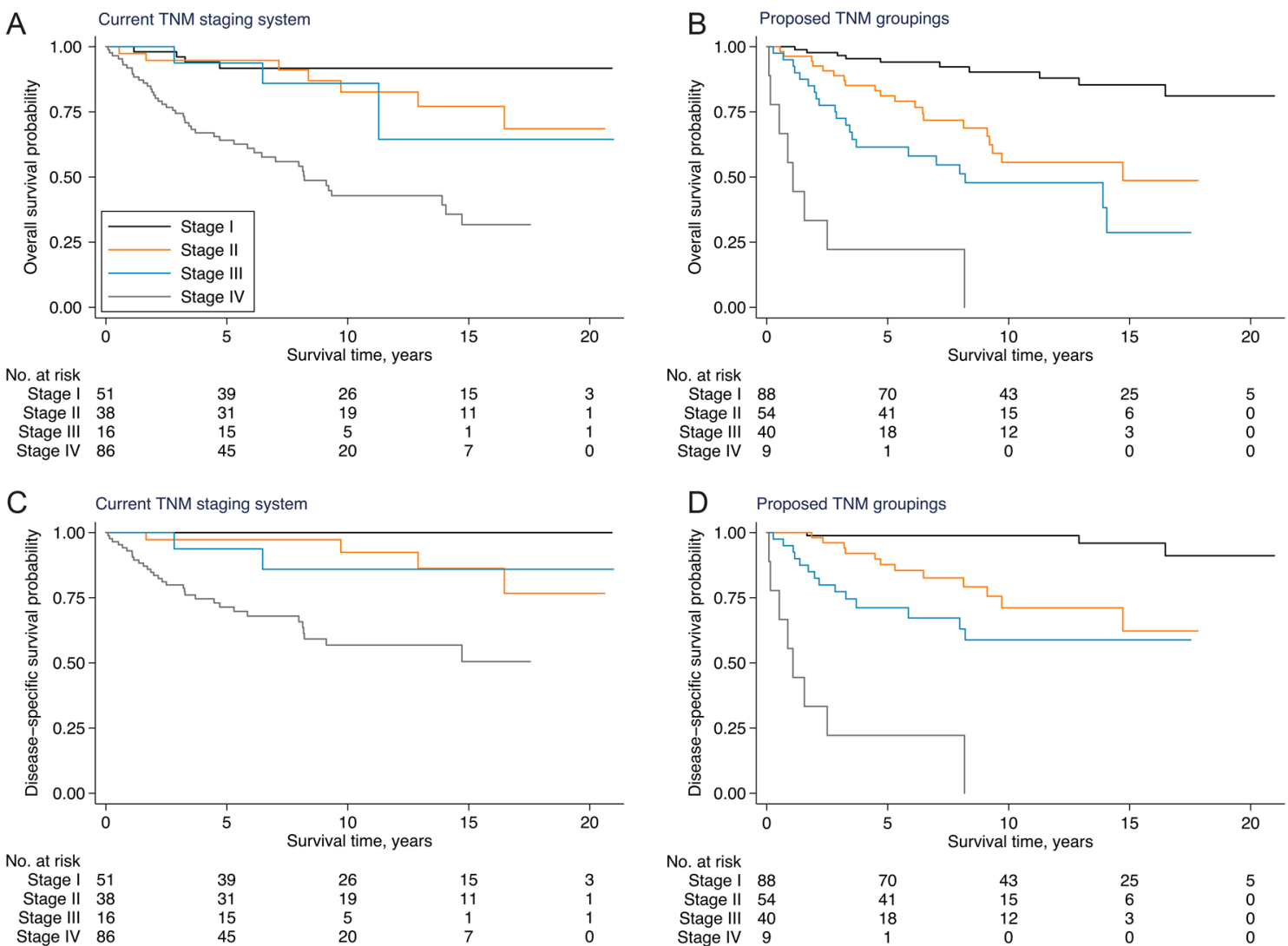

Figure 1

Overall and disease-specific survival in 191 patients with medullary thyroid carcinoma in Denmark 1997-2014 according to the current ${ }^{\mathrm{a}}$ and proposed TNM staging system ${ }^{\mathrm{b}}$. M, metastasis; N, node; T, tumor. aStaging was based on the American Joint Committee on Cancer 7th and 8th edition (22, 23).

${ }^{\mathrm{b} S t a g i n g ~ w a s ~ b a s e d ~ o n ~ n e w l y ~ p r o p o s e d ~ g r o u p i n g s ~(2) . ~}$

When staging was based on the current AJCC TNM staging system, adjusted overall survival did not differ significantly for stage I vs II $(P=0.662)$, stage II vs III $(P=0.522)$ or stage III vs IV $(P=0.082)$. Meanwhile, when using the proposed TNM groupings, adjusted overall survival was significantly different for stage I vs II $(P=0.006)$ and stage III vs IV $(P<0.001)$, but not stage II vs III $(P=0.605)$. Similar results were obtained after Bonferroni correction.

\section{Discussion}

In this nationwide study, we compared the current AJCC TNM staging system to the newly proposed TNM groupings and found that the latter provides better differentiation of mortality risk for stage I vs II and stage III vs IV.

\section{Limitations}

Our sample size is relatively small, providing lesser statistical power to detect differences in survival among the stage groups. We cannot exclude that this was the case for stage II vs III under the proposed TNM groupings. However, it was no issue in the comparison of stage I vs II and stage III vs IV, as significant differences in survival were seen in both cases, even after Bonferroni correction.

Our adjusted analysis of survival did not include the covariates: annual income, insurance and hospital type seen in the study of the proposed TNM groupings (2).

Table 3 Five-year survival in 191 patients with medullary thyroid carcinoma in Denmark 1997-2014 according to the current $^{\mathrm{a}}$ and proposed TNM staging system ${ }^{\mathrm{b}}$.

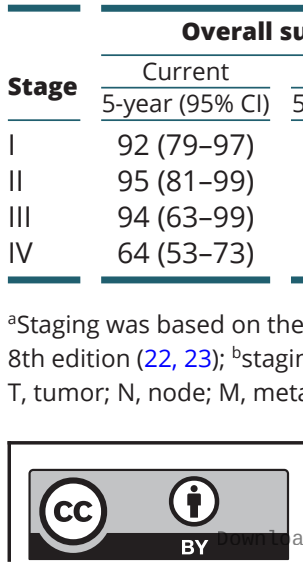
This work is licensed under a Creative Commons Attribution 4.0 International License. 
Table 4 Adjusted ${ }^{a}$ overall survival in 191 patients with medullary thyroid carcinoma in Denmark 1997-2014 according to the current ${ }^{\mathrm{b}}$ and proposed TNM staging system ${ }^{\mathrm{c}}$.

\begin{tabular}{|c|c|c|}
\hline \multirow{2}{*}{ Stage } & Current & Proposed \\
\hline & $\mathrm{HR}(95 \% \mathrm{Cl})$ & $\mathrm{HR}(95 \% \mathrm{Cl})$ \\
\hline | & 1.00 & 1.00 \\
\hline II & $1.32(0.38-4.57)$ & 3.04 (1.38-6.67) \\
\hline III & $2.06(0.45-9.39)$ & $3.59(1.61-8.03)$ \\
\hline IV & $5.87(2.02-17.01)$ & $59.26(20.53-171.02)$ \\
\hline $\mathrm{AlC}^{\mathrm{d}}$ & 508 & 489 \\
\hline
\end{tabular}

${ }^{a}$ Adjusted for age, sex and year of diagnosis; ${ }^{b}$ staging was based on the American Joint Committee on Cancer 7th and 8th edition (22, 23); 'staging was based on newly proposed groupings (2); dlowest AIC indicates best fitted statistical model.

AIC, Akaike information criterion; HR, hazard ratio; M, metastasis; N, node; $T$, tumor.

However, adjustment for these covariates in a Danish setting would seem redundant, partly because medical care is free for all inhabitants, treatment of thyroid cancer is centralized to university hospitals only and partly because income and insurance in earlier multivariate analysis have been reported as non-significant predictors of overall survival (30).

For the purpose of this study, our cohort was trimmed according to the study cohort of the investigation proposing the new TNM groupings. For example, the investigation excluded patients $<18$ years at diagnosis from their study cohort (2) although inclusion may have been an option (31). Similarly, we excluded this patient group from our cohort. Thus, along with the other exclusion criteria, the reproducibility of the proposed TNM groupings in an unselected MTC population may be compromised. However, when reanalyzing data for the 218 patients with pertinent data from our initial cohort of 220 unselected patients, we still find a significant difference in adjusted overall survival for stage I vs II $(P=0.014)$ and stage III vs IV $(P<0.001)$ under the proposed TNM groupings.

\section{Survival}

Our results of better survival discrimination for stage I vs II and stage III vs IV under the proposed TNM groupings are in agreement with the study proposing the new groupings (2). While better distinction between stage II and III under the proposed TNM groupings compared to the current AJCC TNM staging system may be somewhat dubious in our data set, it is indisputable for stage III vs IV. Presumably, this is explained by the fact that stage IV in the proposed TNM groupings only includes patients with distant metastases, while the current AJCC TNM staging system also includes patients with $\mathrm{T} 4$ or N1b disease having no evidence of distant metastases (Table 1). Thus, the current AJCC TNM staging system seems to attenuate the significance of distant metastases, despite the fact that several population-based studies report distant metastases as one of the absolute strongest prognostic indicators for survival in multivariate analysis $(7,32,33,34,35,36)$.

In fact, stage IV has previously consisted of patients with distant metastases only (37) as in the proposed TNM groupings (2). This was changed in 2002 in the sixth edition of the AJCC TNM staging system, where stage IV was expanded to also include patients with T4 or N1b disease regardless of distant metastases status (38). Later an institutional study, investigating the survival of 173 MTC patients according to the fifth and sixth edition of the AJCC TNM staging system found that patients with stage III and IV disease had similar disease-free survival and overall survival under the sixth edition. This led to the conclusion that the sixth edition of the AJCC TNM staging system appeared inadequate, especially for patients with stage IV disease (3) Stage IV, however, has not been changed since 2002 .

In our study, the proposed TNM groupings also demonstrated better survival distinction than the current AJCC TNM staging system for stage I vs II. This may be explained by the downstaging of small tumors (T1-2) with lateral neck metastases (N1b) from stage IV in the current AJCC TNM staging system to stage II in the proposed TNM groupings (Table 1 ).

\section{Conclusion}

The newly proposed TNM groupings appear to provide better survival discrimination in the nationwide Danish MTC cohort than the current AJCC TNM staging system. Adaption of the proposed TNM groupings by the current AJCC TNM staging system may potentially improve accurateness in survival discrimination. However, before such an adaption, further population-based studies securing external validity are needed.

\section{Declaration of interest}

The authors declare that there is no conflict of interest that could be perceived as prejudicing the impartiality of the research reported.

\section{Funding}

This work was supported by the University of Southern Denmark, the Region of Southern Denmark, Odense University Hospital, Copenhagen 
University Hospital, the Danish Cancer Society, the Danish Cancer Research Foundation and the A. P. Moller Foundation. The research salary of Ulla Feldt-Rasmussen is sponsored by an unrestricted research grant from the Novo Nordic Foundation.

\section{Author contribution statement}

J S Mathiesen conceived and coordinated the study, collected data, performed data analyses and drafted the manuscript. S Möller performed data analyses and drafted the manuscript. J P Kroustrup, P Vestergaard, P L Løgstrup, Å K Rasmussen, U Feldt-Rasmuseen, S Schytte, S C Londero, H B Pedersen, C H Hahn, J Bentzen, M Gaustadnes, M Rossing, F C Nielsen, $\mathrm{K}$ Brixen and C Godballe participated in data collection, data analyses and drafting of the manuscript.

\section{References}

1 Mathiesen JS, Kroustrup JP, Vestergaard P, Stochholm K, Poulsen PL, Rasmussen AK, Feldt-Rasmussen U, Schytte S, Londero SC, Pedersen $\mathrm{HB}$, et al. Incidence and prevalence of sporadic and hereditary MTC in Denmark 1960-2014: a nationwide study. Endocrine Connections 20187 829-839. (https://doi.org/10.1530/ EC-18-0157)

2 Adam MA, Thomas S, Roman SA, Hyslop T \& Sosa JA. Rethinking the current American Joint Committee on cancer TNM staging system for medullary thyroid cancer. JAMA Surgery 2017152 869-876. (https://doi.org/10.1001/jamasurg.2017.1665)

3 Boostrom SY, Grant CS, Thompson GB, Farley DR, Richards ML, Hoskin TL \& Hay ID. Need for a revised staging consensus in medullary thyroid carcinoma. Archives of Surgery 2009144 663-669. (https://doi.org/10.1001/archsurg.2009.122)

4 Jin LX \& Moley JF. Surgery for lymph node metastases of medullary thyroid carcinoma: a review. Cancer 2016122 358-366. (https://doi. org/10.1002/cncr.29761)

5 Modigliani E, Cohen R, Campos JM, Conte-Devolx B, Maes B, Boneu A, Schlumberger M, Bigorgne JC, Dumontier P, Leclerc L, et al. Prognostic factors for survival and for biochemical cure in medullary thyroid carcinoma: results in 899 patients. The GETC Study Group. Groupe d'Etude des Tumeurs a Calcitonine. Clinical Endocrinology 199848 265-273. (https://doi.org/10.1046/j.13652265.1998.00392.x)

6 Raue F. German medullary thyroid carcinoma/multiple endocrine neoplasia registry. German MTC/MEN Study Group. Medullary Thyroid Carcinoma/Multiple Endocrine Neoplasia Type 2. Langenbeck's Archives of Surgery 1998383 334-336. (https://doi.org/10.1007/s004230050143)

7 Qu N, Shi RL, Luo TX, Wang YL, Li DS, Wang Y, Huang CP \& Ji QH. Prognostic significance and optimal cutoff of age in medullary thyroid cancer. Oncotarget 20167 15937-15947. (https://doi. org/10.18632/oncotarget.7556)

8 Esfandiari NH, Hughes DT, Yin H, Banerjee M \& Haymart MR. The effect of extent of surgery and number of lymph node metastases on overall survival in patients with medullary thyroid cancer. Journal of Clinical Endocrinology and Metabolism 201499 448-454. (https://doi. $\operatorname{org} / 10.1210 /$ jc.2013-2942)

9 Machens A \& Dralle H. Prognostic impact of N staging in 715 medullary thyroid cancer patients: proposal for a revised staging system. Annals of Surgery 2013257 323-329. (https://doi. org/10.1097/SLA.0b013e318268301d)

10 Tuttle RM \& Ganly I. Risk stratification in medullary thyroid cancer: moving beyond static anatomic staging. Oral Oncology 201349 695-701. (https://doi.org/10.1016/j. oraloncology.2013.03.443)

11 Merkow RP, Rademaker AW \& Bilimoria KY. Practical guide to surgical data sets: national cancer database (NCDB). JAMA Surgery 2018153 850-851. (https://doi.org/10.1001/jamasurg.2018.0492)
12 Doll KM, Rademaker A \& Sosa JA. Practical guide to surgical data sets: surveillance, epidemiology, and end results (SEER) database. JAMA Surgery 2018153 588-589. (https://doi.org/10.1001/ jamasurg.2018.0501)

13 Londero SC, Mathiesen JS, Krogdahl A, Bastholt L, Overgaard J, Bentsen J, Hahn CH, Schytte S, Pedersen HB, Christiansen P, et al. Completeness and validity in a national clinical thyroid cancer database: DATHYRCA. Cancer Epidemiology 201438 633-637. (https://doi.org/10.1016/j.canep.2014.07.009)

14 Gjerstorff ML. The Danish cancer registry. Scandinavian Journal of Public Health 201139 42-45. (https://doi. org/10.1177/1403494810393562)

15 Bjerregaard B \& Larsen OB. The Danish pathology register. Scandinavian Journal of Public Health 201139 72-74. (https://doi. org/10.1177/1403494810393563)

16 Mathiesen JS, Kroustrup JP, Vestergaard P, Madsen M, Stochholm K, Poulsen PL, Krogh Rasmussen A, Feldt-Rasmussen U, Schytte S, Pedersen $\mathrm{HB}$, et al. Incidence and prevalence of multiple endocrine neoplasia 2B in Denmark: a nationwide study. Endocrine-Related Cancer 201724 L39-L42. (https://doi.org/10.1530/ERC-17-0122)

17 Mathiesen JS, Stochholm K, Poulsen PL, Vestergaard EM, Christiansen P \& Vestergaard P. Aggressive medullary thyroid carcinoma in a ten-year-old patient with multiple endocrine neoplasia 2B due to the A883F mutation. Thyroid 201525 139-140. (https://doi.org/10.1089/thy.2014.0177)

18 Mathiesen JS, Habra MA, Bassett JHD, Choudhury SM, Balasubramanian SP, Howlett TA, Robinson BG, GimenezRoqueplo AP, Castinetti F, Vestergaard P, et al. Risk profile of the RET A883F germline mutation: an international collaborative study. Journal of Clinical Endocrinology and Metabolism 2017102 2069-2074. (https://doi.org/10.1210/jc.2016-3640)

19 Godballe C, Jorgensen G, Gerdes AM, Krogdahl AS, TybjaergHansen A \& Nielsen FC. Medullary thyroid cancer: RET testing of an archival material. European Archives of Oto-rhino-laryngology 2010267 613-617. (https://doi.org/10.1007/s00405-009-1115-4)

20 Mathiesen JS, Dossing H, Bender L \& Godballe C. Medullary thyroid carcinoma in a 10-month-old child with multiple endocrine neoplasia 2B. Ugeskrift for Laeger 2014176 V07130456.

21 Mathiesen JS, Kroustrup JP, Vestergaard P, Stochholm K, Poulsen PL, Rasmussen AK, Feldt-Rasmussen U, Gaustadnes M, Orntoft TF, van Overeem Hansen T, et al. Distribution of RET mutations in multiple endocrine neoplasia 2 in Denmark 1994-2014: a nationwide study. Thyroid 201727 215-223. (https://doi.org/10.1089/thy.2016.0411)

22 Amin MB, Edge SB, Greene FL, Byrd DR, Brookland RK, Washington MK, Gershenwald JE, Compton CC, Hess KR, Sullivan DC, et al. AJCC Cancer Staging Manual, 8th ed. New York, NY: Springer, 2017.

23 Edge SB, Byrd DR, Compton CC, Fritz AG, Greene FL \& Trotti A. AJCC Cancer Staging Manual, 7th ed. New York, NY: Springer, 2010.

24 Bland JM \& Altman DG. Multiple significance tests: the Bonferroni method. BMJ 1995310 170. (https://doi.org/10.1136/ bmj.310.6973.170)

25 Mathiesen JS, Kroustrup JP, Vestergaard P, Stochholm K, Poulsen PL, Rasmussen AK, Feldt-Rasmussen U, Gaustadnes M, Orntoft TF, Rossing M, et al. Founder effect of the RET(C611Y) mutation in multiple endocrine neoplasia 2A in Denmark: a nationwide study. Thyroid 201727 1505-1510. (https://doi.org/10.1089/thy.2017.0404)

26 Sondergaard Pedersen JH \& Schaffalitzky De Muckadell O. Choroidal metastases in multiple endocrine neoplasia type $2 \mathrm{~B}$. Acta Ophthalmologica Scandinavica 200785 120-121. (https://doi. org/10.1111/j.1600-0420.2006.00669.x)

27 Hansen HS, Torring H, Godballe C, Jager AC \& Nielsen FC. Is thyroidectomy necessary in RET mutations carriers of the familial medullary thyroid carcinoma syndrome? Cancer 200089 863-867. (https://doi.org/10.1002/1097-0142(20000815)89:4<863::AIDCNCR19>3.0.CO;2-Z)

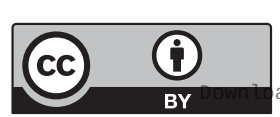

This work is licensed under a Creative Commons Attribution 4.0 International License. ded from Bioscientifica com at 04/26/2023 12:40:18PM 
28 Emmertsen K. Screening for hereditary medullary cancer in Denmark. Henry Ford Hospital Medical Journal 198432 238-243.

29 Mathiesen JS, Kroustrup JP, Vestergaard P, Stochholm K, Poulsen PL, Krogh Rasmussen A, Feldt-Rasmussen U, Schytte S, Pedersen HB, $\mathrm{Hahn} \mathrm{CH}$, et al. Incidence and prevalence of multiple endocrine neoplasia 2A in Denmark 1901-2014: a nationwide study. Clinical Epidemiology 201810 1479-1487. (https://doi.org/10.2147/CLEP. S174606)

30 Youngwirth LM, Adam MA, Scheri RP, Roman SA \& Sosa JA. Extrathyroidal extension is associated with compromised survival in patients with thyroid cancer. Thyroid 201727 626-631. (https://doi. org/10.1089/thy.2016.0132)

31 Youngwirth LM, Adam MA, Thomas SM, Roman SA, Sosa JA \& Scheri RP. Pediatric thyroid cancer patients referred to high-volume facilities have improved short-term outcomes. Surgery 2018163 361-366. (https://doi.org/10.1016/j.surg.2017.09.042)

32 Cox C, Chen Y, Cress R, Semrad AM, Semrad T, Gosnell JE \& Campbell MJ. Are there disparities in the presentation, treatment and outcomes of patients diagnosed with medullary thyroid cancer?-An analysis of 634 patients from the California Cancer Registry. Gland Surgery 20165 398-404. (https://doi.org/10.21037/gs.2016.04.02)

33 Roman S, Lin R \& Sosa JA. Prognosis of medullary thyroid carcinoma: demographic, clinical, and pathologic predictors of survival in
1252 cases. Cancer 2006107 2134-2142. (https://doi.org/10.1002/ cncr.22244)

34 Kuo EJ, Sho S, Li N, Zanocco KA, Yeh MW \& Livhits MJ. Risk factors associated with reoperation and disease-specific mortality in patients with medullary thyroid carcinoma. JAMA Surgery 2017153 52-59. (https://doi.org/10.1001/jamasurg.2017.3555)

35 Gilliland FD, Hunt WC, Morris DM \& Key CR. Prognostic factors for thyroid carcinoma. A population-based study of 15,698 cases from the Surveillance, Epidemiology and End Results (SEER) program 1973-1991. Cancer 199779 564-573. (https:// doi.org/10.1002/(SICI)1097-0142(19970201)79:3<564::AIDCNCR20>3.0.CO;2-0)

36 Mathiesen JS, Kroustrup JP, Vestergaard P, Poulsen PL, Stochholm K, Rasmussen Å, Feldt-Rasmussen U, Schytte S, Londero SL, Pedersen HB, et al. Survival and long-term biochemical cure in medullary thyroid carcinoma in Denmark 1997-2014: a nationwide study. Thyroid 2019 [in press].

37 Fleming ID, Cooper JS, Henson DE, Hutter RVP, Kennedy BJ, Murphy GP, O'Sullivan B, Sobin LH \& Yarbro JW. AJCC Cancer Staging Manual, 5th ed. Philadelphia, PA, USA: Lippincott-Raven, 1997.

38 Greene FL, Page DL, Fleming ID, Fritz AG, Balch CM, Haller DG \& Morrow M. AJCC Cancer Staging Manual, 6th ed. New York, NY, USA: Springer, 2002.

Received in final form 23 November 2018

Accepted 14 December 2018

Accepted Preprint published online 14 December 2018

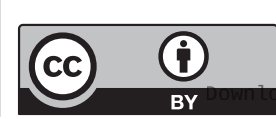

This work is licensed under a Creative Commons Attribution 4.0 International License.

ded from Bioscientifica.com at 04/26/2023 12:40:18PM 